\title{
IDEOLOGI MELUKAT DALAM PRAXIS KESEHATAN
}

I Wayan Artana ${ }^{a}$

Program Studi Keperawatan, STIKES Bina Usada Bali

\begin{abstract}
This article works through about ideology melukat and its role in patient doctor relationship. Ideology grasp is utilized in two different way. First, descriptive purification: as 'system thinks ', 'trusty system ', 'symbolic praktice' one is engaged social action and politics (neutral conception of ideology). Both of, mendasar's ala ideology is engaged process power relationship justification that asymmetric, in reference to justification process dominates (ideologies critical conception). Its quick is place growths melukat giving room managinging to get affix significant. Melukat also clear away doctor practice room as therapy of alternative complementary.
\end{abstract}

Keywords Melukat, Doctor, Alternative complementary

\section{PENDAHULUAN}

Tubuh manusia yang utuh, merupakan saling keterkaitan antara anta karana sarira, sukma sarira, dan stula sarira (tri sarira). Masing-masing bagian mempunyai otonomi tersendiri, akan tetapi bagian satu dengan lainnya saling berkaitan (fungsional). Mengacu kepada konsep tri sarira tersebut, kesehatan seseorang dipahami sebagai sehat jasmani dan rohani: sehat secara fisik, mental, dan spiritual. Akan tetapi pada kenyataannya di masyarakat, tidaklah demikian adanya. Seseorang dikatakan sehat, hanya didasarkan kepada berfungsinya badan fisik saja (stula sarira). Bila, mereka tidak dapat beraktifitas secara fisik, barulah mereka dikatakan sakit atau merasakan sakit.

Pemahaman yang masih monosemi tersebut, membuktikan proses edukasi masyarakat tentang sehat belumlah menunjukkan hasil yang optimal. Padahal kesehatan juga dapat terganggu akibat

\footnotetext{
a wayan.artana473@gmail.com
} 
bermasalahnya stula sarira (emosi, pikiran, kecerdasan). Masyarakat postmodern menyadari bahwa, kebahagiaan tidak hanya didapat diluar dirinya, sehingga mereka dalam menjalani kehidupan tidak terus terpaku kepada kehidupan fisik semata tetapi juga kehidupan perasaan dan pikiran.

Sesungguhnya persoalan besar manusia bukanlah masalah-masalah ekonomi, politik, atau teknologi, tetapi justru pertanyaan yang ada di relung hatinya untuk mengerti keberadaan manusia yang terbatas ini, tentang tujuan hidup dan nilai hidup, serta bagaimana cara untuk mendapatkannya.

Seringkali ditemukannya ketidakbahagiaan yang diakibatkan, bukan karena kurangnya pemenuhan fisik akan tetapi, karena ketidakmampuannya untuk mengelola perasaan dan pikiran. Untuk mencapai kebahagiaan maka, diperlukan ketenangan pikiran, kemampuan untuk mengelola perasaan, serta mendahulukan pikiran rasional dibandingkan perasaan. Pikiran dan emosi sebagai penentu apakah seseorang dapat menjadi bahagia atau tidak.

Kegoncangan emosi yang berlarut-larut dan tidak mendapatkan penanganan yang memadai, dapat mengganggu fungsi dari tubuh, yang lama kelamaan menggerogoti organorgannya menjadi rusak. Untuk itu, penanganan yang ditujukan hanya kepada kelainan fisik, dipastikan tidak akan memberikan hasil yang memuaskan. Perlu dilakukan penanganan komplementer- alternatif bagi kelainan emosinya. Tentunya, penanganan ini tetap bertujuan untuk menghilangkan penyebab utama dari penyakitnya.

Sebagai orang yang percaya dengan hal transedental, rasa bersalah (emosi) sering menghantui dalam kehidupan sehari-hari. Rasa ini muncul, karena adanya perilaku yang dirasakan menyimpang dari tradisitradisi yang berlaku. Rasa bersalah, rasa tidak mampu, rasa tertekan, bahkan rasa tidak berguna di dunia ini, dapat menimbulkan stres, kecemasan, frustasi, depresi, bahkan sampai melakukan tindakan bunuh diri. Seperti yang diberitakan dalam media seperti pada Koran Tribun tanggal 23 September 2017, penyebab bunuh diri di Kabupaten Buleleng, karena faktor kecemasan, depresi, kelainan fisik, dan faktor ekonomi. Begitu juga, akibat kecemasan karena menderita sakit hipertensi, rematik, serta stroke yang lama, seorang ibu rumah tangga melakukan bunuh diri di daerah Abiansemal pada tanggal 30 April 2018. Kasus bunuh diri karena kecemasan juga terjadi di daerah Selemadeg Barat pada tanggal 17 Februari 2018 (Bali Post, 19 Pebruari 2018).

Hal ini membuktikan bahwa, rasa-rasa negatif yang menghinggapi seseorang perlu dilakukan "pembersihan" atau sering diistilahkan dengan dilakukan penglukatan, yang bermakna pembersihan pikiran dan jiwa secara spiritual dalam diri manusia. Penyucian secara rohani ini akan 
menghilangkan pengaruh kotor (klesa ) dalam diri. Dengan dilakukannya penglukatan ini, diharapkan tri sarira kembali dalam keadaan "bersih".

Sering kita melihat baik dimedia sosial, media cetak, dan media elektronik, pada hari-hari tertentu apalagi hari yang dianggap hari suci oleh masyarakat Bali, masyarakat berduyun-duyun datang ke tempat melukat. Mereka memenuhi tempat-tempat melukat untuk mendapatkan keinginan yang menjadi tujuannya. Hampir di seluruh kabupaten ada satu tempat penglukatan. Sebut saja di Kabupaten Gianya ada Tampaksiring dan Sebatu. Di Kabupaten Badung ada permandian Mumbul, di Kabupaten Tabanan ada Tamba Waras, di Kabupaten Bangli ada Pancoran Sudamala, dan masih ada yang lainnya.

\section{PEMBAHASAN}

John B. Thomson (2007) pada bukunya "Analisis Ideologi", Kritik Wacana Ideologi-Ideologi Dunia, menunjukkan bahwa istilah ideologi digunakan dalam dua cara yang sangat berbeda. Di satu sisi, ideologi digunakan oleh beberapa penulis sebagai sebuah istilah yang murni deskriptif: sebagai 'sistem berpikir', 'sistem kepercayaan', 'praktik-praktik simbolik' yang berhubungan dengan tindakan sosial dan politik (konsepsi netral dari ideologi). Di sisi lain, ideologi secara mendasar berhubungan dengan proses pembenaran hubungan kekuasaan yang tidak simetris, berhubungan dengan proses pembenaran dominasi (konsepsi kritis ideologi). Penggunaan konsepsi kritis, mengandung konotasi negatif yang selalu mengikat analisa ideologi pada pertanyaan kritis.

Asal mula teori ideologi diawali oleh pertentangan dan perselisihan, maka tahun-tahun belakangan teori ini diperkaya dan dielaborasi melalui refleksi "bahasa", sehingga ide-ide berputar dalam dunia sosial sebagai ucapan-ucapan, ekspresi, sebagai kata-kata yang berbicara atau mengesankan. Bersandarkan pada pendapat Thomson di atas, pembahasan mengenai ideologi melukat akan dilakukan pada sudut pandang berbeda, yaitu melukat dalam artian yang murni deskriptif, melukat sebagai rasionalisasi suatu tindakan, dan melukat sebagai kuasa wacana.

\section{Melukat Membersihkan Jiwa dan Badan}

Melukat merupakan bagian dari pelaksaan upacara manusa yadnya, yang memiliki tujuan untuk membersihkan dan menyucikan pribadi secara lahir dan batin. Pembersihan akan hal-hal negatif dan malapetaka akibat pengaruh dari hasil perbuatan-perbuatan masa lampau yang masih memengaruhi kita sampai sekarang maupun dari perbuatan hidup saat ini. Upacara ini merupakan adat tradisi umat Hindu Bali yang secara turun-temurun masih dilaksanakan hingga kini. 
Dalam Pustaka Suci "Manawa Dharma Sastra" Bab V sloka 109, dinyatakan sebagai berikut :

Adbhir gatrani cuddhyanti, manah satyena cuddhyti, cidyatapobhyam buddhir jnanena cuddhyatir

Artinya :

Tubuh dibersihkan dengan air, pikiran dibersihkan dengan kejujuran, roh dengan ilmu dan tapa, akal dibersihkan dengan kebijaksanaan.

Tri sarira, sebagai penyusun yang utuh tubuh manusia, merupakan satu kesatuan antara fisik, pikiran, dan jiwa. Stula sarira merupakan badan materiil,terdiri dari berbagai macam organ dan sistem organ. Sistem-sistem organ ini menjalankan fungsinya sehingga tubuh dapat melakukan tugasnya atau fungsinya. Sedangkan sukma sariramerupakan badan halus adalah komponen tubuh berisi pikiran. Dalam hal ini, ada pikiran yang telah tersimpan, disebut juga ingatan atau memori (citta), pikiran yang sedang beproses atau berpikir (manah), pikiran emosi (ahangkara), dan pikiran kecerdasan (buddhi). Jiwa atau Roh dalam hal ini adalah "badan penyebab".

Pada hakikatnya, manusia adalah makhluk yang religius, mereka selalu terdorong untuk menciptakan dunia yang penuh makna (Turner dan Bryan, 2006:15). Peter Berger, dalam karyanya The Social Reality of Religion, mengatakan bahwa agama merupakan sebuah proses pembentukan simbol-simbol. Proses ini menempatkan manusia sebagai aktor produksi untuk memenuhi kebutuhan diri. Dalam memproduksi, manusia menempatkan segala emosi dan pikirannya dalam proses produksi, sampai hasil dari produksinya. Tidak mengherankan, pada hasil produksinya yang berupa tanda ataupun simbol tertanam "belahan jiwanya" sebagai pemberi makna.

Segala sesuatunya merupakan ciptaan serta perwujudan jiwa (anta karana sarira). Artinya, jiwa sebagai pembuat, pemilik, pengatur, penikmat segala yang ada. jiwa akan mewujudkan "diriNya" pada setiap ciptaan, terjalin pada "badan" lain pembentuk tubuh. Karena kemampuan manusia terbatas sedangkan, kemampuan Tuhan tak terbatas, keinginan manusia untuk mengetahui Tuhan secara utuh melalui "badan kasar" panca indra tidaklah mungkin dilakukan. Manusia berusaha mewujudkan Tuhan dalam simbol, tanda, atau alat yang dibuatnya untuk memuja Tuhan (pantheisme), dan mengharapkan Tuhan menyenangkan hati manusia dengan mewujudkan diriNya pada simbol atau tanda tersebut. Itulah keMahakuasaan Tuhan.

Sejalan dengan Peter Berger dan pemahaman di atas, bila dihayati secara mendalam maka, melukat menggunakan sarana air untuk pembersihan tubuh secara lahir (sekala) yaitu membersihkan stula sarira, "badan kasar". Melukat akan melepaskan segala sesuatu yang melekat pada tubuh. Badan fisik dilekati oleh kotoran yang berupa 
benda-benda fisik, sedangkan emosi dan pikiran dilekati oleh guna (sifat). Karena berada dalam ranah pikiran dan emosi, melukat lebih mendekati pembersihan kejiwaan secara khusus dan pembersihan badan secara umum. Melukat, juga diartikan sebagai melepaskan (tentang barang yang dilekatkan pada tubuh) atau melakukan suatu pekerjaan untuk melepaskan sesuatu yang melekati tubuh. Kedua pengertian di atas, mempunyai dasar pemahaman yang sama yaitu membersihkan diri.

Dalam bukunya The Elementary Forms of Religious, Emile Durkheim mengatakan agama sebagai "suatu sistem yang terpadu mengenai kepercayaan-kepercayaan praktek- praktek yang berhubungan dengan benda-benda suci atau benda-benda khusus (terlarang)". Kepercayaan-kepercayaan dan praktek-praktek yang menyatu dalam satu komunitas disebut umat. Durkheim juga mengabstraksi kehidupan beragama dengan memisahkan antara yang sakral dengan yang profan.

Sakral berupa ritual-ritual keagamaan, simbol-simbol yang penuh makna religius. Jadi, sakral dalam keagamaan, mulai dari simbolsimbol, proses ataupun ritual, insentif berupa "rasa hati" yang gembira, di dalam kesemuanya itu ada tertanam emosi dan pikiran. Sehingga, melukat dapat dikatakan sebagai hal yang sakral. Profan adalah peristiwa yang biasa terjadi dalam masyarakat dikehidupan sehari-harinya yang tidak memiliki nilai-nilai suci yang disakralkan. Yang profan ini dapat menjadi sakral jikalau masyarakat mengagungkan dan menyucikannya.

Melukat bertujuan untuk membersihkan pikiran dan emosi dari sifat-sifat yang melekatinya, sehingga ia akan menjadi murni kembali. Dengan begitu, melukat dalam ritualnya menggunakan berbagai macam simbol-simbol seperti sarana upakara, mantra, dan air. Sarana upakara sebagai wujud pemberitahuan kepada Tuhan Yang Maha Esa/Ida Sang Hyang Widhi Wasa bahwa akan dilakukan penglukatan, juga sebagai wujud bhakti dan permohonan kepadaNYA agar Beliau berkenan melepaskan "kotoran" yang melekat pada diri. Air yang sudah disucikan dengan kekuatan mantra (tirtha pengelukatan) sebagai simbol alat untuk melepaskan kotoran.

\section{Melukat Sebagai Gaya Hidup Modern}

Gaya hidup (lifestyle) adalah bagian dari kebutuhn sekunder manusia dan berubah sesuai dengan perjalanan waktu, perkembangan jaman, atau perubahan situasi (Hemamalini, 2017:20). Gaya hidup juga merupakan cara atau bagaimana seseorang menjalankan aktifitasnya, apa yang penting orang pertimbangkan pada lingkungannya (minat), dan apa yang mereka pikirkan tentang dirinya sendiri dan dunia sekitarnya (opini). Lain lagi yang dikatakan oleh Minor dan Mowen (2002: 282), bahwa gaya hidup menunjukkan bagaimana orang 
hidup, bagaimana membelanjakan uangya, dan bagaimana mengalokasikan waktunya. Tidak jauh berbeda dengan pendapat diatas, Suratno dan Rismiati (2001: 174-175) menjelaskan pola hidup seseorang dalam dunia kesehariannya yang dinyatakan dalam kegiatan, minat, dan pendapat yang bersangkutan. Gaya hidup ini mencerminkan keseluruhan pribadi yang berinteraksi dengan lingkungan. Bagi Kotler (2002:191-192) gaya hidup merupakan pola perilaku dalam kehidupan seseorang di dunia yang diekspresiakn dalam keseluruhan aktivitas, minat, maupun opininya. Sehingga gaya hidup ini menggambarkan keseluruhan dan "keutuhan" diri seseorang dalam berinteraksi dengan lingkungannya.

Sejalan dengan pemikiran Kotler, di Bali dewasa ini dipertontonkan fenomena melukat yang merasuki lapisan-lapisan mayarakat. Tidak saja dilakukan oleh anak-anak, remaja, dewasa, bahkan para lansiapun ikut berbondongbondong melakukan penglukatan. Mereka mengharapkan sesuatu dari kegiatan tersebut, untuk menyenangkan bahkan dapat membahagiakan dirinya. Dalam membentuk budaya citra (image culture) dan budaya cita rasa (taste culture) peranan iklan yang menawarkan gaya visual yang kadang-kadang mempesona dan memabukkan sangat besar. Iklan merepresentasikan gaya hidup dengan menanamkan secara halus (subtle) arti penting citra diri untuk senantiasa tampil di muka publik, sehingga iklan juga perlahan dan pasti memengaruhi pilihan cita rasa masyarakat (Chaney, 2006:55). Budaya menjadi popular oleh mayoritas masyarakat dan kemudian mempraktekkannya. Pengenalan tempat-tempat melukat menggunakan media sosial, sering dapat dilihat di kelompok-kelompok media sosial. Promosi yang gencar, menjadikan tempat tersebut dikenal banyak orang, sehingga pengunjungpun akan makin bertambah.

Akan tetapi, bagi masyarakat yang kapitalis, karena menyadari melukat telah menjadi gaya hidup masyarakat, kondisi ini dipergunakan sebagai suatu peluang untuk dijadikan lahan menghasilkan uang. Mereka juga berlomba-lomba menyediakan suatu fasilitas (baca;tempat melukat). Tempattempat yang dulunya disucikan, sekarang diperbaiki, dihias, dan dipromosikan untuk menarik minat warga datang menggunakannya. Yang lebih menarik lagi, munculnya tempat-tempat melukat yang baru ikut meramaikan "pasar" melukat.

\section{Ideologi Melukat Di dalam Ruang Praktek Dokter}

Kepuasan seseorang (baca; pasien) akan terpenuhi bila mereka sembuh dari penyakitnya, akan tetapi kepuasan akan menjadi lebih besar bila pasien memperoleh haknya dan diberikan melaksanakan kewajibannya. Untuk itu, seorang pelayan kesehatan harus menyadari, 
bahwa pekerjaan penyembuh itu mengambil bagian dari karya Tuhan, sehingga seorang dokter berkewajiban menyembuhkan pasiennya secara menyeluruh (Daldiyono, 2007:vii-ix).

Seperti dijelaskan di atas, tubuh manusia merupakan satu kesatuan antara stula sarira, sukma sarira, dan ananta karana sarira. Sehingga, penyembuhan secara menyeluruh harusnya juga memperhatikan kesembuhan terhadap emosi dan pikiran (sukma sarira). Akan tetapi, ilmu kedokteran konvensional (modern) adalah kedokteran positivistik, yang dalam bertindak selalu berdasarkan fakta empiris. Segala sesuatunya harus dapat dicandra oleh panca indra, sedikit ruang yang disediakan untuk kebebasan

pasien menginterpretasikan penyakitnya. Pengetahuan kedokteran digunakan demi pengetahuan, yaitu teori yang dipisahkan dari praxis hidup manusia. Positivisme menganggap pengetahuan mengenai fakta obyektif sebagai pengetahuan yang sahih, dengan menyingkirkan pengetahuan yang melampaui fakta. Asimetrisnya pengetahuan kesehatan yang dimiliki dokter (lebih tinggi), menjadikan ia lebih superior dihadpan pasien. Keadaan ini, tentunya tidak menjadikan hubungan dokter dengan pasien berdasarkan keyakinan, tetapi hanya sampai batas kepercayaan. Keadaan ini, sewaktuwaktu bisa menimbulkan kekerasan terhadap dokter ataupun pasien dan keluarganya.
Untuk itu, pendapat Habermas yang mengatakan bahwa, perubahan tidak dapat dipaksakan secara revolusioner melalui "jalan kekerasan". Juga, tidak dapat dipastikan datangnya seperti gerahana matahari. Memaksakan perubahan revolusioner melalui kekerasan hanyalah akan menggantti kekerasan lama dengan kekerasan baru. Di lain pihak, masyarakat memang tidak akan berubah selama anggotanya menunggu akan datangnya perubahan bagaikan menunggu terjadinya gerhana. Transpormasi sosial perlu diperjuangkan melalui dialog emansipatoris. Hanya melalui"jalan komunikasi" dan bukan kekerasan dapat diwujudkan interaksi yang berkeyakinan (Hardiman, 2013: 3435).

Dengan memakai pedoman pendapat Habermas di atas, dalam hubungan dokter-pasien perlu ditinjau kembali. Ilmu kedokteran yang positivistik, memisahkan ilmu kedokteran dengan hal-hal yang praxis, perlu dikomunikasikan kembali agar terjadi bios theoriticos yaitu suatu "jalan" untuk mengolah dan mendidik jiwa dengan membebaskan manusia (baca;dokterpasien) dari perbudakan oleh doxa (pendapat) dan dengan jalan ini dokter-pasien mencapai otonomi dan kebijaksanaan hidup.

Kenyamanan dokter-pasien dalam interaksi pengobatan pada tingkat kepercayaan, menandakan masih adanya kecurigaan diantara keduanya, tetapi kecurigaan ini bisa 
diterima oleh kedua belah pihak. Hubungan yang sampai pada tingkat kepercayaan ini, menjadikan hubungan dokter-pasien dalam suasana membutuhkan sekaligus mencurigakan (rindu tapi benci). Bagaimana seorang dokter mewacanakan penyakit yang diderita pasien, merupakan cerminan apakah seorang dokter memahami secaraholistik pasiennya. Kemauan dokter untuk mau mendengarkan keluhan pasien, tidak saja tentang penyakitnya, akan tetapi juga tentang hal-hal di luar kesehatan, menjadikan dokter lebih banyak tahu tentang penyakit pasiennya. Seorang dokter yang mengggunakan keadaan sakitnya pasien untuk membuat pasien menuruti apa kemauan darinya (dokter), menandakan bahwa si dokter belumlah paham betul dengan keadaan pasiennya.

Lain sekali dengan hubungan pada tingkat keyakinan. Pada tingkat ini ditandai dengan tidak adanya selubung kecurigaan lagi dalam hubungan dokter-pasien. Mereka saling mempunyai keyakinan terhadap apa yang dikatakan maupun apa yang akan dilakukan. Masingmasing pihak dalam suasana ini, mau mendengarkan dan memahami apa yang dikatakan oleh pihak lainnya, sehingga tidak ada penolakan apalagi pemaksaan kehendak dalam interaksi dokter-pasien. Suasana ini memperkecil permasalahan yang akan muncul dalam interaksi dokterpasien.

Untuk sampai pada tingkat keyakinan, perlu usaha-usaha dari dokter dalam memahami pasiennya. Karena, penyebab penyakit bukanlah hal-hal fisik saja akan tetapi, berperanan juga hal-hal emosional, alangkah baiknya dokter memposisikan dirinya sebagai pendengar baik, merubah sikap "aku sudah tahu" menjadi "aku ingin tahu". Sehingga, pemahaman dokter akan keadaan fisik, fisiologis, sosial, spiritual, dan emosi pasiennya menjadi lebih baik. Perubahan interaksi dokter-pasien dari tingkat kepercayaan menuju keyakinan tak dapat dipaksakan secara instan. Komunikasi dan pemahaman memegang peranan sentral dalam interaksi dokter-pasien. Perlu suatu ketekunan dan sustainable untuk saling memahami dianta dokter dengan pasien, sehingga apa yang menjadi tujuan dari interaksi kesehatan tersebut dapat terwujud, tanpa ada meninggalkan bekas-bekas kecurigaan.

Keinginan dari individu agar diberikan kebebasan dalam menginterpretasikan dirinya dalam hal sakit-sehat dan kebebasan individu dalam memilih pelayanan kesehatan, membuat Organisasi Kesehatan Dunia (WHO) melakukan redifinisi tentang apa itu sehat. Paradigma lama mengatakan sehat itu hanya bebas dari penyakit fisik, akan tetapi paradigma sekarang mendefinisikan sehat tersebut merupakan suatu keadaan sejahtera dari fisik, mental (emosi dan jiwa), sosial, dan bukan hanya suatu keadaan bebas dari penyakit, cacat, dan kelemahan (penderitaan). 
Implikasi dari redifinisi tersebut, memberikan kebebasan pasien untuk memilih tempat pelayanan kesehatan, memilih dokter yang disenangi atau yang cocok dengannya, bahkan boleh menolak rencana-rencana dokter yang akan dilakukan terhadap dirinya (pasien). Redifinisi ini juga, dapat mengurangi kuasa wacana pengobatan dari dokter, karena pasien mempunyai kebebasan dalam memilih obat ataupun cara pengobatan yang dikehendaki. Dokter harus mampu memberikan keyakinan kepada pasien tentang rencana-rencana tindakan yang akan dilakukan, agar pasien menjadi lebih paham serta mau secara iklas menjalani rencanarencana dari dokter. Tentunya, integritas dokter menjadi sangat penting di hadapan pasien.

Bila dikaitkan dengan obat dan cara pengobatan, redifinisi ini membawa konsekwensi, bahwa ilmu kedokteran yang positivistik tidak lagi dapat dipaksakan kepada pasien. Kuasa wacana dokter tentang obatobatan sudah mulai berkurang, karena pasien punya kebebasan dalam memilih obat yang dipakai. Pasien tidak harus hanya menggunakan obat-obatan konvensional, pengobatan alternatifpun diijinkan, sepanjang tidak menggangu pengobatan konvensional. Berbagai macam cara dan bahan dapat dipakai sebagai pengobatan alternatif. Begitu juga budaya (baca; melukat) dan tradisi lainnya bisa digunakan sebagai pengobatan. Pengobatan alternatif lebih banyak digunakan pada pasien yang mengalami penyakit pada sukma sarinya (pikiran, emosi).

\section{PENUTUP}

Melukat merupakan suatu budaya yang ada di Bali bertujuan untuk membersihkan badan halus (suksma sarira). Sarana-sarana penglukatan berupa sarana upakara, air, dan mantra. Melukat, juga diartikan sebagai melepaskan segala sesuatu yang melekat di badan kasar (stula sarira). Tapi dalam pelaksanaannya hanya menggunakan sarana air saja. Artinya, melukat untuk membersihkan stula sarira sama dengan mandi biasa.Pada era sekarang ini, melukat sudah menglami komodifikasi dari yang sakral menuju kehidupan yang profan, dengan dibukanya tempattempat melukat secara umum, mulai dikenakan tarif (beaya) masuk, serta keharusan mengikuti aturan-aturan dari pengelola tempat pengelukatan. Dengan dipahaminya lebih mendalam tentang tubuh, yang terdiri dari tiga bagian penting (badan fisik, badan pikiran, serta jiwa), melukat juga memasuki ruang praktek kedokteran, sebagai pengobatan komplementeralternatif untuk melengkapi pengobatan konvensional, sehingga kesembuhan pasien terjadi secara menyeluruh.

\section{DAFTAR PUSTAKA}

Agus, Bustanuddin. 2006. Agama dalam Kehidupan Manusia Pengantar Antropologi agama. 
Jakarta: PT Raja Grafindo

Persada.

Cavallaro, Dani. 2004 Critical and Cultural Theory, Teori Kritis Dan Teori Budaya. (Penerjemah : Laily Rahmawati). Yogyakarta. Niagara.

Chaney, David. 2006. Lifestyle: Sebuah Pengantar Komprehensif. Jogyakarta: Jalasutra

Dister Ofm, Nico Syukur. 1988. Pengalaman dan Motivasi Beragama. Yogyakarta : Kanisius.

Garfinkel MS, Schumacher HR Jr, Husain A, Levy M, Reshetar RA. 1994. Evaluation of a Yoga Based Regimen for Treatment of Osteoarthritis of the Hands. The Journal of Rheumatology, Vol. 21(12):2341-2343.

Hemamalini, Kade. 2017. Yoga Sebagai Lifestyle Masyarakat Postmodern di Bintaro Jaya. Disertasi (tidak diterbitkan). Denpasar: Program Doktor Ilmu Agama dan Kebudayaan Pasca Sarjana Universitas Hindu Indonesia.

Jannah, Miftakhul. 2004. Pelatihan Meditasi-Otogenik untuk Meningkatkan Konsentrasi pada Atlet Lari Jarak Pendek.
Tesis. Yogyakarta: Universitas Gadjah Mada.

Kotler, Philip. 2002. Manajemen Pemasaran analisis Perencanaa, Implementasi dan Kontrol. Edisi Kesembilan, jilid 1 dan 2. Jakarta: Prehalindo, alih bahasa oleh Hendara Teguh dan Ronny a.Rusli.

Mowen.John C dan Minor, M. 2002. Perilaku Konsumen. Jakarta: Erlangga.

Pudja,G. 2002. Bhagawad Gita (Pancama Veda). Surabaya: Paramita

Putra, I G AG. 1998. Wrhaspati Tattwa. Surabaya: Paramita

Suratno,B\& Rismiati,C.2001. Pemasaran Barang dan Jasa. Yogyakarta: Kanisius.

Thomson, B. John. 2007. Analisis Ideologi Kritik Wacana Ideologi-Ideologi

Dunia.(Penerjemah Haqqul Yaqin). Yogyakarta: IRCiSoD.

Turner dan Bryan, 2006. Agama dan Teori Sosial. Yogyakarta: IRCiSoD.

Wijaya, IKM. 2015. Ruang Ritual pada Sumber Mata Air dan Aliran Air di Bali. In: Prosiding Seminar Nasional CEMTECS 2015: Pengembangan Infrastruktur 
Sumber Daya Air di Indonesia. Fakultas Teknik Universitas Hindu Indonesia, pp. 426-436.

Yogi Meranggi. 2018. Melukat; a Purification by Water. Bali Tourism Journal, Vol. 2 No. 1, p. 6-9. 